\title{
Cavernous malformation of the trigeminal nerve
}

L. Mascarenhas; F. Magalhães*; Z. Magalhães**; H. Romão; M. Resende; J. Resende-Pereira**; M. Honavar* and A. Rocha Vaz

Neurosurgery Service. *Anatomic Pathology Service. **Neuroradiology Service. Pedro Hispano Hospital. Matosinhos. Portugal.

\section{Summary}

A cavernous malformation involving the Gasserian ganglion, $2^{\text {nd }}$ and $3^{\text {rd }}$ divisions of the trigeminal nerve on the left side was resected via an extradural route in a 54 year old male. Cavernous malformations of the cranial nerves are rare. Specific origin from the trigeminal nerve has not been previously reported.

Key Words: Cavernous malformation. Trigeminal nerve. Surgery.

\section{Malformacion cavernosa del nervio trigémino}

\section{Resumen}

Una malformación cavernosa afectando el ganglio de Gasser, la segunda y tercera divisiones del nervio trigémino fue resecada por vía extradural en un varón de 54 años. Las malformaciones de los nervios craneales son raras. Su origen específico en el nervio trigémino no ha sido descrito previamente.

PALABRAS CLAVE: Malformación cavernosa. Nervio trigémino. Cirugía.

\section{Introduction}

Cavernous malformations may affect diverse components of the nervous system ${ }^{1}$. The frequency however is variable and proportional to the volume occupied by each structure. Cranial nerve involvement therefore is not a common finding.

\section{Case Report}

A 54-year-old, previously healthy, man presented with a one year history of pain and dysesthesia referred to the face and fronto-temporal regions on the left side. Hypoes-

Recibido: 28-02-05. Aceptado: 17-03-05 thesia was found in the territory supplied by the second division of the left trigeminal nerve. Visual acuity, visual fields on confrontation and eye motility were all normal. The remaining of the neurological examination was unremarkable. Magnetic resonance (MR) imaging showed two space occupying lesions, one in the region of Meckel's cave and neighboring floor of the left middle fossa, and another in the posterior third of the falx cerebri (figure 1). Meningioma was the main diagnostic hypothesis for both lesions, but schwannoma was also considered for the middle fossa lesion. The patient's complaints and deficits were attributed mainly to the middle fossa lesion. Surgical exploration was therefore undertaken by the senior author (ARV). A frontotemporal craniotomy was employed. A pretemporal intradural transylvian approach disclosed a mass covered by dura arising from the Gasserian ganglion. These findings were not compatible with a meningioma of the middle fossa floor, and hence, an extradural route to the lesion was opted for. The dura of the middle fossa floor was peeled away. The second and third divisions of the trigeminal nerve were identified and the mass was seen between the two, extending towards the Gasserian ganglion. The lesion was of firm consistency, moderately hemorrhagic and somewhat adherent to the nerves. It was totally removed in a piecemeal fashion taking care to preserve the remaining rootlets of the second and third divisions of the trigeminal nerve. The postoperative course was uneventful. Histological examination of the lesion disclosed a cavernous malformation (figure 2). Some degree of hypoesthesia in the territory supplied by the second and third divisions of the trigeminal nerve, the latter due to surgical manipulation, persisted in the 4 month follow-up visit. Complaints of pain and dysesthesia subsided. The postoperative control MR scan confirmed total resection of the lesion and stability of the lesion of the falx cerebri (figure 3).

\section{Discussion}

In a recent review, only 44 cases of cavernous malformations of the cranial nerves were found in the literature, namely in the optic pathways, VII / VIII nerve complex, 

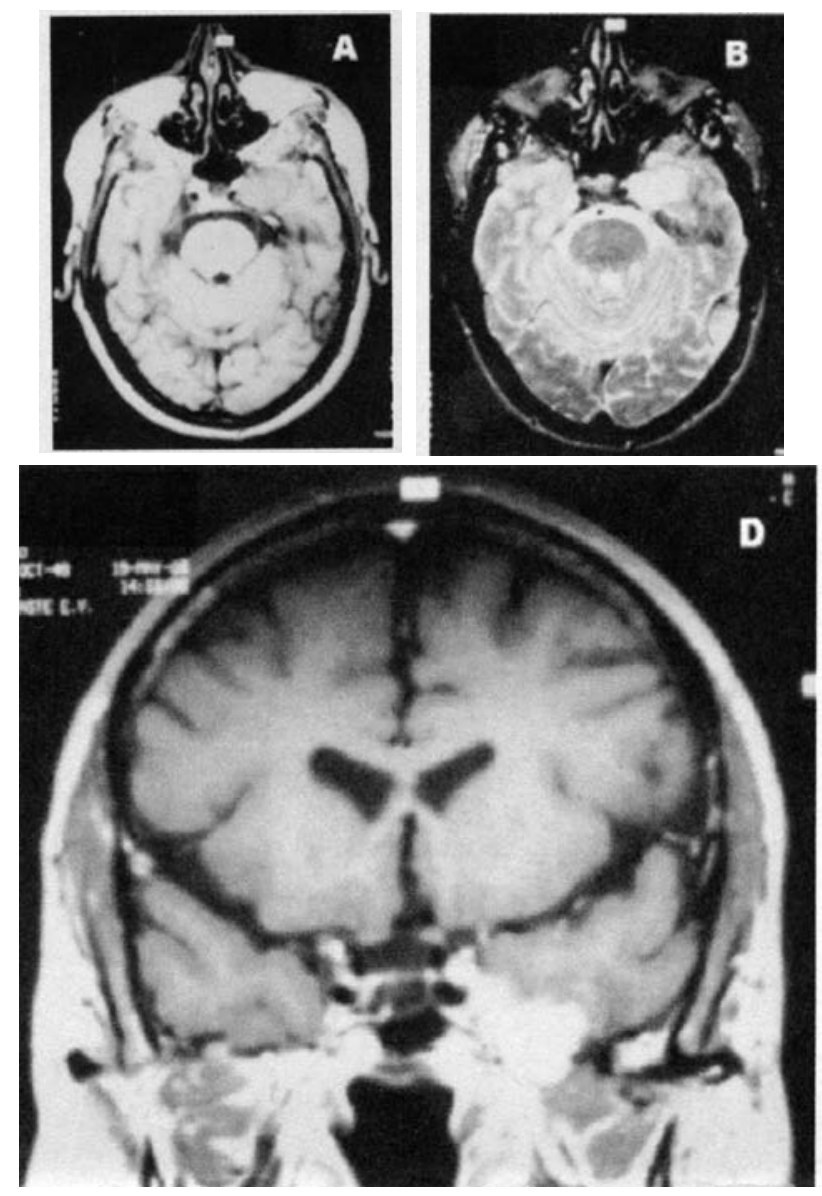

2006; 17: 72-75

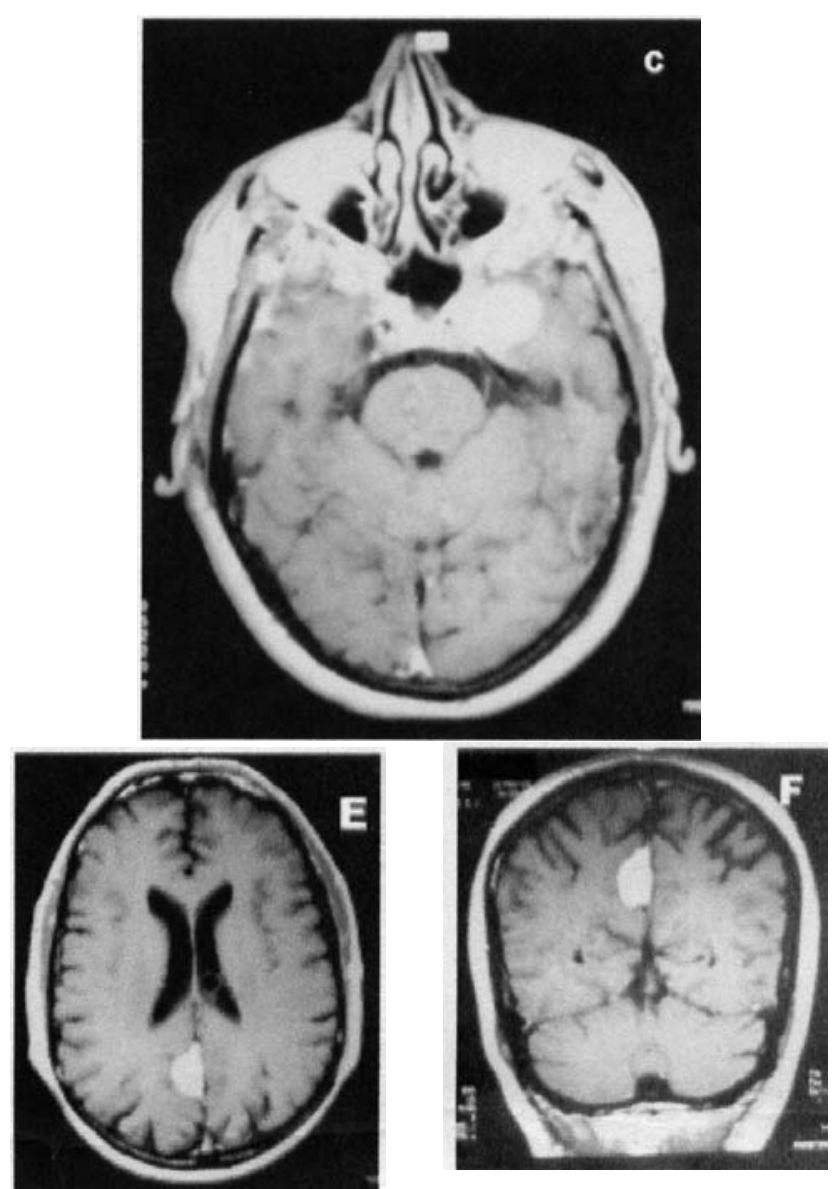

Figure 1. MR images: A T1 weighted axial slice; $B$ - T2 weighted axial slice; $C$ - T1 weighted axial slice after contrast enhancement; D - T1 weighted coronal slice after contrast enhancement; $E$ T1 weighted axial slice after contrast enhancement; $F$ - T1 weighted coronal slice after contrast enhancement. A mass measuring 31x20x25mm is seen in left Meckell's cave and surrounding area $(A, B, C, D)$. The lesion has a small extension to the infratemporal fossa through the foramen ovale (D). Another mass is seen arising from the posterior third of the falx cerebri and growing towards the right (E, F). Both lesions are isointense on $T 1$ and hyperintense on $T 2$ weighted sequences $(A, B)$. There is enhancement after gadolinium injection $(C$, $D, E, F)$. Some compression of the adjacent brain parenchyma is seen but there isn't any surrounding edema.
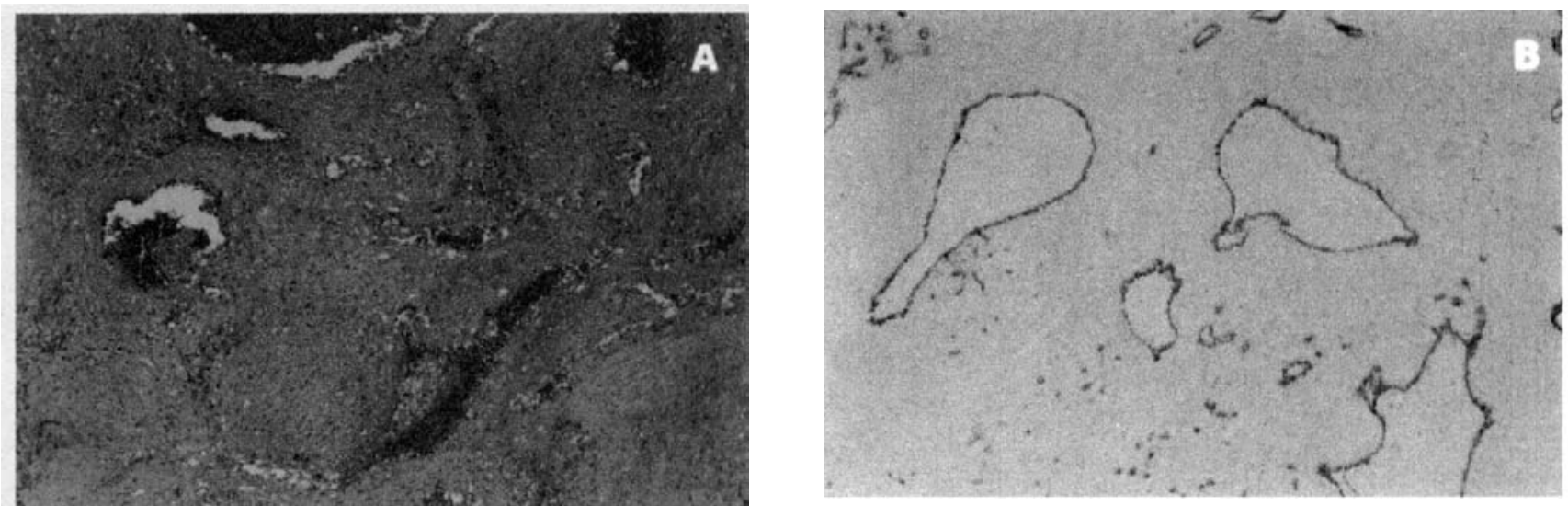

Figure 2. Histological features of the lesion. A: large number of thick walled vessels of different caliber, some with dilated lumina, others with luminal compression (hematoxylin and eosin staining). B: CD34 immunocytochemistry demonstrating the endothelial cell lining of the vessels.. 

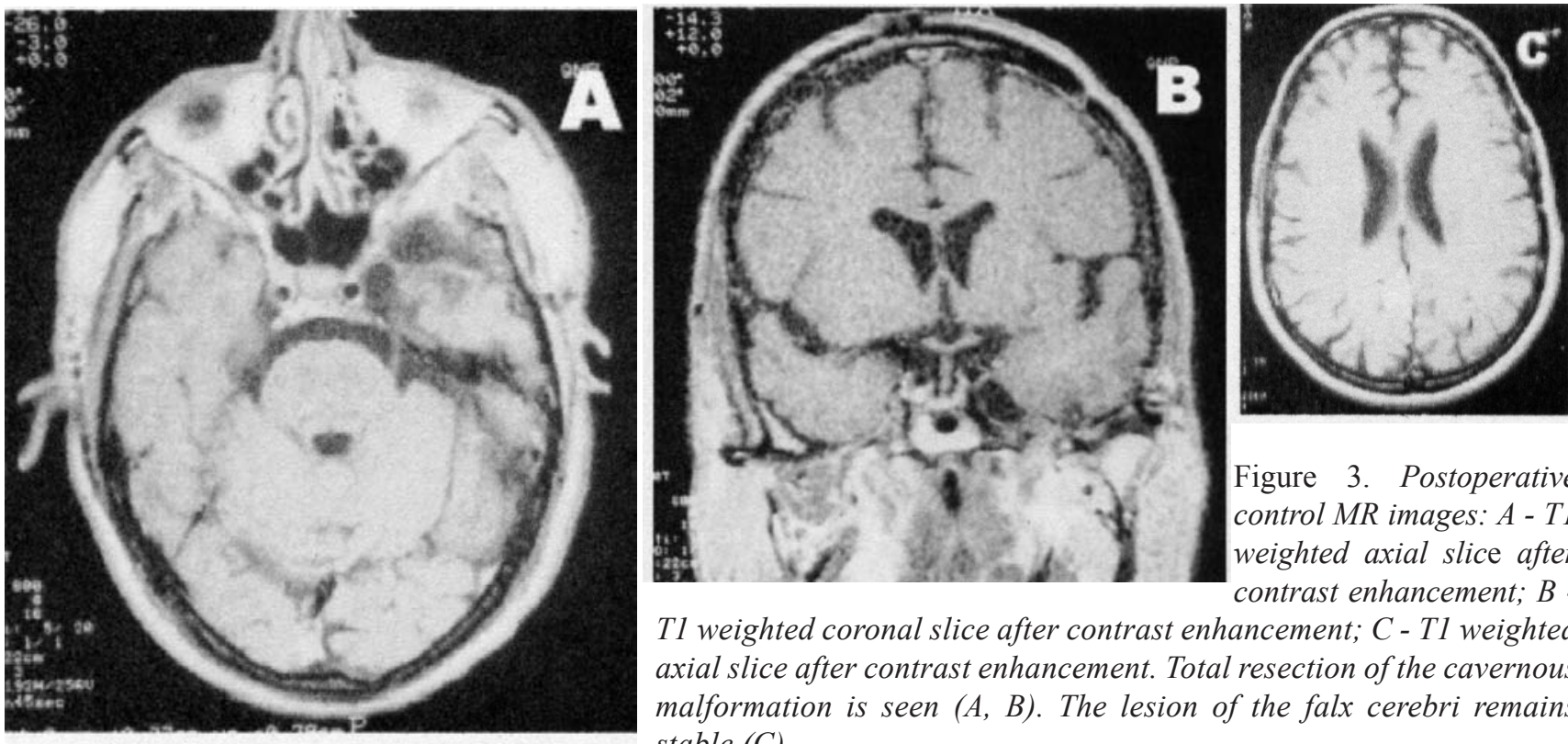

Figure 3. Postoperative control MR images: $A$ - T1 weighted axial slice after contrast enhancement; $B$ $T 1$ weighted coronal slice after contrast enhancement; $C$ - T1 weighted axial slice after contrast enhancement. Total resection of the cavernous malformation is seen $(A, B)$. The lesion of the falx cerebri remains stable $(C)$.

III nerve, XII nerve and cerebellopontine angle nerves not otherwise specified ${ }^{2}$. This appears to be the first case of a surgically and histologically confirmed cavernous malformation specifically originating from the trigeminal nerve. The lesion was extra-cavernous, i.e. different from the more common cavernous sinus cavernous malformations where clear identification of the origin is virtually impossible.

Rapid progression of symptoms, nondiagnostic radiological characteristics, and the importance of total surgical resection were features stressed in the above-cited review. In this case as well, preoperative MR imaging did not raise the possibility of the diagnosis. The characteristic findings of a core of mixed signal intensity surrounded by a hypointense rim in T2 weighted images were absent. Instead, the homogeneous appearance of the lesion and contrast enhancement were more consistent with a tumor. Similar diagnostic difficulties have been reported for dural cavernous malformations ${ }^{5}$.

A good final outcome was achieved with surgery, the standard recommended treatment ${ }^{2}$. Radiosurgery has been reported as an option for cavernous sinus cavernous malformations, and can probably be considered for Meckel's cave region as well, but experience is as yet scarce, under evaluation, and includes histologically unconfirmed cases $^{3,4}$.

\section{References}

1. Arnin-Hanjani, S., Ojemann, R.G., Ogilvy, C.S.: Surgical management of cavernous malformations of the nervous system. In: Schmidek, H.H., ed. Schmidek \& Sweet Operative Neurosurgical Techniques. Indications, Methods and Results. $4^{\text {th }}$ ed. Philadelphia: WB Saunders Company, 2000: 1347-62.

2. Deshmukh, V.R., Albuquerque, F.C., Zabramski, J.M., et al.: Surgical management of cavernous malformations involving the cranial nerves. Neurosurgery 2003; 53: 352357.

3. Nakamura, N., Shin, M., Tago, M., et al.: Gamma knife radiosurgery for cavernous hemangiomas in the cavernous sinus. Report of three cases. J Neurosurg (Suppl 5) 2002; 97: 477-480.

4. Peker, S., Kilic, T., Sengoz, M., et al.: Radiosurgical treatment of cavernous sinus cavernous hemangiomas. Acta Neurochir 2004; 146: 337-341.

5. Rosso, D., Lee, D.H., Ferguson, G.G., et al.: Dural cavernous angioma: a preoperative diagnostic challenge. Can J Neurol Sci 2003; 30: 272-277.

Mascarenhas, L.; Magalhães, F.; Magalhães, Z.; Romão, H.; Resende, M.; Resende Pereira, J.; Honavar, M.; Rocha Vaz, A.: Cavernous malformation of the trigeminal nerve. Neurocirugía 2006; 17: 64-67.

Correspondencia postal: Dr. Lino Mascarenhas. Servico de Neurocirurgia. Hospital Pedro Hispano. Rua Dr. Eduardo Torres. 4454-509 Matosinhos. Portugal. 
Cavernous malformation of the trigeminal nerve

\section{Comments}

This is a concise and well-elaborated case report on a cavernous malformation of the trigeminal nerve, for which the authors must be commended. Cerebral cavernous malformations (CCM) are hamartomatous vascular malformations characterized by abnormally enlarged capillary cavities without intervening brain tissue. Clinical presentation usually consists of cerebral hemorrhage or seizures. CCMs may also constitute incidental neuroimaging findings.

I would like to add some references for completeness. Agozzino et al. ${ }^{1}$ described a cavernous hemangioma of the Gasserian ganglion. Asari et al. ${ }^{2}$ have documented two instances of trigeminal neurinoma presenting with tumoral hemorrhage in which histopathological study demonstrated telangiectatic or cavernomatous vessels. Fehlings and Tucker have also reported a cavernous hemangioma at the Meckel's cave ${ }^{3}$. Most interesting is the paper of Kasantikul et al. on an unusual neurilemmoma of the trigeminal nerve that included a cavernous angioma, cartilage, bone and adipose tissue relating this association to ectomesenchymal properties of the neural crest. Poca et al. ${ }^{6}$ have also illustrated a case of CCM involving the extracranial divisions of the trigeminal nerve.

Most CCMs are congenital in nature, with some familial predisposition ${ }^{5}$. Genetic aspects of CCMs are presently being studied ${ }^{5}$. CCM may also be acquired, especially those instances appearing after radiotherapy. The development of
Neurocirugía 2006; 17: 64-67

acquired cases of CCM raises the very interesting question of the potential role of tumoral angiogenetic factors in the development of de novo CCMs and opens up the possibility of treating some special instances of CCM with inhibitors of angiogenesis (angiostatin etc.).

\section{References}

1. Agozzino, L., Giordana, M.T., Mignini, R., Moraci, A.: Angioma del ganglio de Gasser. Considerazione morfologiche ed istogenetiche su di un caso. Riv Neurol 1981; 51: 287-296.

2. Asari, S., Tsuchida, S., Fujiwara, A., et al.: Trigeminal neurinoma presenting with intratumoral hemorrhage: report of two cases. Clin Neurol Neurosurg 1992; 94: 219-224.

3. Fehlings, M.G., Tucker, W.S.: Cavernous hemangioma of Meckel's cave. Case report. J Neurosurg 1988; 68: 645647.

4. Kasantikul, V., Brown, W.J., Netsky, M.G.: Mesenchymal differentiation in trigeminal neurilemmoma. Cancer 1982; 50: 1568-1571.

5. Laurans, M.S., DiLuna, M.L., Shin, D., et al: Mutational analysis of 206 families with cavernous malformations. J Neurosurg 2003; 99: 38-43.

6. Poca, A., Colosimo, C., Tirpakova, B., Lauriola, L., Di Rocco, F.: Cavernous hemangioma extending to extracranial, intracranial, and orbital regions. Case report. J Neurosurg 2004; 101: 1057-1060. 